Tecnología y

Ciencias $\cong$ Agua
2020, Instituto Mexicano de Tecnología del Agua

Open Access bajo la licencia CC BY-NC-SA 4.0

(https://creativecommons.org/licenses/by-nc-sa/4.0/)

DOI: $10.24850 /$ j-tyca-2020-02-02

Artículos

\title{
Innovación social y aportaciones al derecho humano al agua en hogares de la mixteca poblana
}

\section{Social innovation and contributions to the water human right in the Mixteca Poblana households}

Ignacio Ocampo-Fletes ${ }^{1}$, ORCID: 0000-0001-6311-1072

${ }^{1}$ Colegio de Postgraduados, Campus Puebla, Santiago Momoxpan, San Pedro Cholula, Puebla, México, ocampoif@colpos.mx

Autor para correspondencia: Ignacio Ocampo-Fletes, ocampoif@colpos.mx

\section{Resumen}

Se analizaron las aportaciones de una innovación social (cisterna de ferrocemento) al derecho humano al agua en 30 comunidades de nueve municipios de la mixteca baja de Puebla, México. Para captar información sobre dos momentos del entorno del agua en el hogar (antes y después de construir la cisterna), se aplicó una encuesta a 221 jefes y jefas de familia participantes en un programa público. Asimismo, se realizaron mediciones directas a 221 cisternas para calcular el 
Tecnología y

Ciencias $₫$ Agua
2020, Instituto Mexicano de Tecnología del Agua

Open Access bajo la licencia CC BY-NC-SA 4.0

(https://creativecommons.org/licenses/by-nc-sa/4.0/)

volumen captado de agua. Con base en los factores pactados en la observación general núm. 15 (2002) del derecho al agua (artículos 11 y 12 del Pacto Internacional de Derechos Económicos, Sociales y Culturales), se establecieron indicadores y los resultados se compararon para identificar cambios. La innovación generó los siguientes efectos: aumentó de 18.3 a $63.2 \%$ la capacidad de almacenamiento por hogar; aumentó de 97.1 a $100.0 \%$ los hogares que disponen de 50 a 100 litros por persona al día; se incrementó de 23.0 a 79.0\% los días que alcanza el agua almacenada; aumentó de 23.5 a $59.3 \%$ las familias que dejaron de acarrear agua; disminuyó de 31.5 a $28.0 \%$ las familias que recorren más de 1000 metros por agua; disminuyó de 20.4 a $19.0 \%$ las familias que se desplazan más de 30 minutos por agua, y se redujo en $29.0 \%$ el costo anual por pago de agua acarreada y comprada de camión cisterna y garrafón. Se concluye que la innovación causó efectos positivos en los hogares, contribuyendo en algunos factores del derecho humano al agua.

Palabras clave: innovación, derecho humano al agua, ecotecnia, agua de uso doméstico, mixteca.

\section{Abstract}

The contributions of a social innovation (ferrocement cistern) to the human right to water were analyzed in 30 communities in nine municipalities of the Mixteca Baja of Puebla, Mexico. To collect information on two moments of the water environment in the home (before and after the cistern was built), a survey was applied to 221 heads of household participating in a public program. Likewise, direct 
Tecnología y

Ciencias $₫$ Agua
2020, Instituto Mexicano de Tecnología del Agua

Open Access bajo la licencia CC BY-NC-SA 4.0

(https://creativecommons.org/licenses/by-nc-sa/4.0/)

measurements were made to 221 cisterns to calculate the collected volume of water. Based on the factors agreed in General Observation No. 15 (2002) on the right to water (articles 11 and 12 of the International Covenant on Economic, Social and Cultural Rights), indicators were established and the results compared to identify changes. The innovation generated the following effects: it increased from 18.3 to $63.2 \%$ the storage capacity per household; increased from 97.1 to $100.0 \%$ households that have between 50 and 100 liters per person per day; increased from 23.0 to $79.0 \%$ on the days the stored water satisfied the needs of the households; increased from 23.5 to $59.3 \%$ families that ceased to carry water; decreased from 31.5 to $28.0 \%$ families who travel more than 1000 meters; decreased from 20.4 to $19.0 \%$ of the families moving more than 30 minutes, and reduced by $29 \%$ the annual cost per payment of water hauled and purchased from water tanker truck and water jugs. It is concluded that innovation caused positive effects on households contributing in some factors of the human right to water.

Keywords: Innovation, human right to water, eco-techniques, water for domestic use, Mixtec.

Recibido: $13 / 02 / 2019$

Aceptado: 08/07/2019 
Tecnología y

Ciencias $\approx$ Agua
2020, Instituto Mexicano de Tecnología del Agua

Open Access bajo la licencia CC BY-NC-SA 4.0

(https://creativecommons.org/licenses/by-nc-sa/4.0/)

\section{Introducción}

El agua es el recurso natural renovable más importante para todas las formas de vida del planeta. No obstante su cantidad, hoy día la humanidad vive un estrés hídrico causado por diversos factores: aumento de la población, cambio climático, crecimiento de las zonas urbanas, privatización, tácticas de oferta y contaminación (Pérez, 2015), así como pobreza, desigualdades y disparidad en las relaciones de poder (ONU \& OMS, 2011).

Para 2015, la escasez ya afectaba a 663 millones de personas que permanecían sin acceso a fuentes mejoradas de agua potable (Semarnat \& Conagua, 2017), y se prevé que para 2025, 1800 millones de personas vivan en países o regiones con escasez absoluta de agua (FAO, 2015).

En América Latina, 130 millones de personas carecen de suministro de agua en sus hogares; sólo una de cada seis cuenta con redes de suministro adecuadas, y millones de seres humanos son privados del agua y excluidos de los sistemas de distribución (Azar, 2018).

Para afrontar la crisis del agua, la comunidad internacional creó conciencia de que el acceso al agua potable debe enmarcarse en los derechos humanos (ONU \& OMS, 2011). Por ello, la Declaración Universal de los Derechos Humanos proclamó el derecho de toda 
Tecnología y

Ciencias $\approx$ Agua
2020, Instituto Mexicano de Tecnología del Agua

Open Access bajo la licencia CC BY-NC-SA 4.0

(https://creativecommons.org/licenses/by-nc-sa/4.0/)

persona a salud, bienestar, alimentación, vestido, vivienda y servicios sociales necesarios (ONU, 1948). El derecho al agua quedó pactado en la observación general núm. 15, Pacto Internacional de los Derechos Económicos, Sociales y Culturales (ONU, 2002).

La Organización de los Estados Americanos (OEA) aprobó la resolución AG/RES.2760 (XLII-O/12), en la que reafirma el derecho de los Estados a establecer políticas sobre el uso y los servicios del agua en sus territorios (OEA, 2013). Se pactó como meta en los objetivos de desarrollo del milenio (meta 7.C) (ONU, 2013), y en los objetivos del desarrollo sostenible (objetivo 6) (ONU \& CEPAL, 2016).

En consecuencia, México modificó el artículo $4^{\circ}$ de la Constitución Política de los Estados Unidos Mexicanos, en el que el Estado garantiza el acceso, disposición y saneamiento de agua de consumo personal y doméstico. En el artículo $27^{\circ}$ establece que las aguas son propiedad de la Nación y otorga a los municipios la responsabilidad del servicio de agua potable (artículo $115^{\circ}$, III a) (Secretaría de Gobernación, 2014).

A pesar de que existen múltiples informes que advierten el problema de acceso y distribución del agua, al igual que diversos instrumentos jurídicos sobre el derecho humano al agua, los Estados no han tenido la capacidad para garantizar el acceso al agua a toda la población de su competencia (Salmón, 2013).

En los países latinoamericanos se ha instituido en las Constituciones Políticas la propiedad de los recursos naturales al Estado, por lo que éste debe proporcionar agua a toda la población, pero tal beneficio no llega a todos de la misma manera (Gentes, 2001). 
Tecnología y

Ciencias $\approx$ Agua
2020, Instituto Mexicano de Tecnología del Agua

Open Access bajo la licencia CC BY-NC-SA 4.0

(https://creativecommons.org/licenses/by-nc-sa/4.0/)

Lo anterior muestra que existe un derecho constitucional declarado en papel, que a través del instrumento de la garantía debe convertirse en un derecho operable, ejecutable y exigible (Mitre, 2012), por lo que el Estado es el responsable de poner los medios y las condiciones para ejercerlos; de lo contrario, se caerá en un ilusionismo constitucional y/o internacional (Azar, 2018). Sin embargo, aun donde el Estado reconoce en sus leyes el derecho al agua, no necesariamente se traduce en el cumplimiento automático del derecho (Langford \& Khalfan, 2006).

Frente a los desafíos sociales y ambientales es necesario buscar nuevas soluciones que permitan afrontar los problemas con recursos más escasos, sobre todo donde el clima se convierte en el principal factor de distribución del agua. Este es el caso de México, donde dos terceras partes del territorio se considera árida o semiárida, con precipitaciones anuales menores a los 500 milímetros (Semarnat, 2016).

Bajo condiciones restrictivas de agua es difícil desarrollar cualquier actividad productiva, más cuando existen necesidades del vital líquido para uso doméstico y personal. Para apoyar a las poblaciones marginadas, el Estado mexicano puso en marcha el programa estratégico de seguridad alimentaria (PESA), enfocado a la producción de alimentos; uno de los componentes es "hogar saludable", principalmente el acceso al agua para uso doméstico.

Una de las regiones en las que operó el programa fue la mixteca baja de Puebla, México. En una microrregión formada por 30 comunidades de nueve municipios, se construyeron 521 cisternas de ferrocemento (considerada innovación social) alternativa más viable en 
Tecnología y

Ciencias
2020, Instituto Mexicano de Tecnología del Agua

Open Access bajo la licencia CC BY-NC-SA 4.0

(https://creativecommons.org/licenses/by-nc-sa/4.0/)

el corto plazo para captar y almacenar agua de lluvia para el periodo de sequía.

Posterior a su implementación fue necesario conocer sus efectos en los beneficiarios, por lo que el objetivo de este estudio fue analizar los aportes de la innovación social al derecho humano al agua, con base en los factores pactados por la Organización de las Naciones Unidas (ONU) en la observación general número 15, Pacto Internacional de los Derechos Económicos, Sociales y Culturales.

\section{El concepto de innovación social}

En términos generales, se considera innovación a la aplicación y el uso de nuevas ideas, conceptos, productos, servicios, prácticas, métodos, etcétera, con el objetivo de aumentar la productividad (Planque, 2002; Amaro, Morales, \& Villavicencio, 2011); pero este concepto está orientado a la empresa, al mercado y a la economía, por lo que otros autores consideran como innovación la "capacidad que tiene la gente de explotar una idea o un nuevo método correctamente para alcanzar un efecto deseado (material o social). Las consecuencias (intencionadas o no) de esta actividad innovadora pueden provocar cambios incrementales, radicales o transformacionales de la vida social" (Smith, 2017). 
Tecnología y

Ciencias $\approx$ Agua
2020, Instituto Mexicano de Tecnología del Agua

Open Access bajo la licencia CC BY-NC-SA 4.0

(https://creativecommons.org/licenses/by-nc-sa/4.0/)

A pesar de que la innovación empresarial es la más generalizada para el bienestar humano, existen otras innovaciones que tienen impactos significativos en la sociedad y que explican la mejora en sus condiciones de vida, que no necesariamente son innovaciones comerciales, sino innovaciones sociales, aunque no hay consenso sobre su significado específico (Pol \& Ville, 2009).

La innovación social es un fenómeno complejo que abarca diversas actividades de innovaciones sociales, que responden a necesidades de la población que no son comercialmente viables, debido a nuevas combinaciones de prácticas sociales, actitudes y valores que implican cambios en estrategias y políticas, estructuras organizacionales y marcos institucionales (Van der Have \& Rubalcaba, 2016). Una innovación para que sea social debe mejorar las condiciones económicas y sociales de la sociedad; es decir, mejorar la calidad de vida (Pol \& Ville, 2009). La innovación social colectiva se origina de las bases sociales, activistas, grupos comunitarios, organizaciones, etcétera, donde las comunidades controlan los procesos y resultados (Boni, BeldaMiquel, \& Pellicer-Sifres, 2018).

Haciendo una diferenciación entre innovaciones sociales e innovaciones tecnológicas, Alijani y Wintjes (2017) consideran que el uso de la tecnología es de valor neutral, y su empleo no garantiza la producción de valor social, pues las innovaciones sociales no están medidas por los precios de mercado que determinan el valor de cambio. Por otro lado, la innovación social está limitada espacial y temporalmente por la diversidad de contextos sociales, económicos, culturales e institucionales. Como fenómeno social, el ritmo y la 


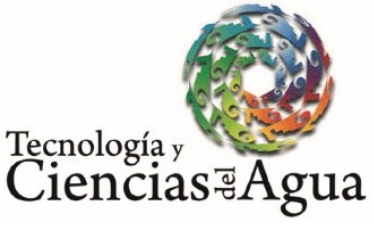

2020, Instituto Mexicano de Tecnología del Agua

Open Access bajo la licencia CC BY-NC-SA 4.0

(https://creativecommons.org/licenses/by-nc-sa/4.0/)

dirección de la innovación social están relacionados de manera estrecha con la dinámica de las relaciones sociales.

Windrum, Schartinger, Rubalcaba, Gallouj y Toivonen (2016) plantean tres áreas de la innovación social al relacionarlas con la innovación para el mercado (de servicio): a) la innovación social tiene un valor social, impulsada por principios de inclusión y bienestar, mientras la innovación para el mercado está orientada por objetivos de lucro, es decir, la creación de ganancia económica; b) las innovaciones sociales buscan empoderar a los ciudadanos, mientras las innovaciones del mercado pretenden empoderar a los ciudadanos a través nuevos roles y relaciones, y el desarrollo de activos y capacidades, y c) las innovaciones sociales tienden a ser de naturaleza muy local y a menudo se dificulta su codificación, mientras que las innovaciones de servicio en ocasiones fomentan la imitación y la rápida difusión de nuevas ideas y prácticas.

Estas características coinciden con los dos elementos conceptuales básicos señalados por Van der Have y Rubalcaba (2016): las innovaciones sociales implican un cambio en las relaciones sociales, sistemas o estructuras, y estos cambios sirven como objetivos humanos compartidos o para resolver problemas socialmente relevantes.

En el mismo sentido, Álvarez-González, García-Rodríguez, Sanzo-Perez y Rey-García (2017) consideran cuatro dimensiones para que un objeto de innovación se considere innovación social: a) estar enfocada al bien común para satisfacer o solucionar problemas sociales; b) ser un proceso colaborativo donde participen todas las partes interesadas; c) implica una mejora en relación con las soluciones 
Tecnología y

Ciencias $\approx$ Agua
2020, Instituto Mexicano de Tecnología del Agua

Open Access bajo la licencia CC BY-NC-SA 4.0

(https://creativecommons.org/licenses/by-nc-sa/4.0/)

previas, y d) supone cambios efectivos en los comportamientos y prácticas sociales en los diferentes niveles.

Por tanto, la innovación de carácter social presenta rasgos que la diferencian de la innovación de carácter económico, como la búsqueda de soluciones a problemas sociales, más que al mercado; el uso del poder intelectual del humano, más que el financiero; la difusión libre, más que la protección de la idea, y su carácter complejo, más que aspectos tecnológicos (Morales, 2008).

En este estudio se consideró innovación social a la introducción de la cisterna de ferrocemento para la captación y el almacenamiento de agua de lluvia. Si bien la prioridad es el agua de lluvia, las fuentes pueden ser otras, como agua de la red pública, agua de pozo o río, agua de camión cisterna, entre otras.

El término ferrocemento fue patentado por el francés Joseph Louis Lambot, en 1855, y concierne a un material similar al hormigón, que se refuerza con varias capas de malla de alambre delgado, como malla hexagonal o de gallinero, malla electro soldada o acma, y algunas piezas de fierro, formando un entramado que se recubre con la mezcla de cemento, arena y agua (mortero), formando un estructura especial con un espesor entre 6 y $8 \mathrm{~cm}$, donde la geometría de la cisterna con forma de cilindro le otorga una rigidez y resistencia adecuadas para la acumulación del agua (Mora, Jiménez, Carrasco, \& Abarca, 2016).

\section{El derecho humano al agua}


Tecnología y

Ciencias $\approx$ Agua
2020, Instituto Mexicano de Tecnología del Agua

Open Access bajo la licencia CC BY-NC-SA 4.0

(https://creativecommons.org/licenses/by-nc-sa/4.0/)

Desde la noción de seguridad hídrica existen dos concepciones sobre derechos de agua: "las que predican la homogeneidad y la universalidad y adoptan una visión de los derechos con normativas centradas en el Estado", que funcionan como herramienta y condición para facilitar el intercambio y el comercio del agua; y los derechos de agua basados "en el reconocimiento explícito de su especificidad histórica y su arraigo en situaciones ecológicas y culturales particulares", constituidas en el entendimiento de las normas vigentes, las prácticas para el control local del agua y las relaciones de poder existentes (Zwarteveen \& Boelens, 2011a).

La concepción del Estado sobre derecho al agua quedó pactado en la observación general núm. 15 del Pacto Internacional de los Derechos Económicos, Sociales y Culturales; fundamenta que el derecho humano al agua "es el derecho de todos a disponer de agua suficiente, salubre, aceptable, accesible y asequible para el uso personal y doméstico", para evitar la muerte, reducir riesgos de enfermedades, satisfacer necesidades de consumo, cocina, higiene personal y domésticas; este derecho es indispensable y condición previa para ejercer otros derechos humanos para una vida digna (ONU, 2002).

El derecho humano al agua consiste en que "todas las personas tengan acceso al vital líquido y puedan utilizarlo en cantidades suficientes y en condiciones adecuadas para que sus necesidades de vida sean satisfechas de manera digna", por lo que se trata de un 
Tecnología y

Ciencias $₫$ Agua
2020, Instituto Mexicano de Tecnología del Agua

Open Access bajo la licencia CC BY-NC-SA 4.0

(https://creativecommons.org/licenses/by-nc-sa/4.0/)

derecho básico inherente al ser humano, común a todos, no objeto de negociación e inalienable (Azar, 2018).

En un enfoque social compatible en algunos aspectos con los enfoques público y comunitario, destaca que la dignidad humana es lo primero, y que el acceso universal al agua suficiente para las necesidades básicas es una prioridad absoluta y no negociable (Langford \& Khalfan, 2006).

Desde la perspectiva del derecho humano al agua de las comunidades y pueblos indígenas, el Sistema Interamericano de Protección de Derechos Humanos considera que el derecho de acceso a agua limpia y de calidad está vinculado con la propiedad del territorio ancestral, por lo que las tierras y los recursos existentes deben protegerse como derecho a su propiedad, para que las comunidades realicen sus costumbres ancestrales, como derecho a la vida cultural, y puedan gozar de una vida digna (Salmón, 2012).

La configuración anterior se enfoca al reconocimiento cultural de la justicia del agua; reconocer y respetar las diferentes formas de tratar, organizar y hablar de agua, basadas en la diversidad, identidad y cultura, otorgando autonomía a las comunidades de usuarios de agua para construir y aplicar sus propias normas (Zwarteveen \& Boelens, 2011b).

Desde la cosmovisión de los pueblos originarios "el agua como derecho universal y comunitario es de todos y es de nadie. Pertenece a la tierra y a los seres vivos, incluyendo al ser humano. Se distribuye equitativamente de acuerdo a necesidades, costumbres y normas comunitarias, y según su disponibilidad cíclica" (Huanacuni, 2010). 
Tecnología y

Ciencias
2020, Instituto Mexicano de Tecnología del Agua

Open Access bajo la licencia CC BY-NC-SA 4.0

(https://creativecommons.org/licenses/by-nc-sa/4.0/)

Algunos países andinos han incluido en sus constituciones este paradigma. En la República de Ecuador, el agua es parte de la Pacha Mama (Madre Naturaleza) y se reconoce al agua como un derecho humano fundamental e irrenunciable, reconocido como los Derechos del Buen Vivir (Asamblea Constituyente, 2008; Martínez, 2017).

Con la misma ideología, en Bolivia, el derecho al agua prioriza su uso, acceso y aprovechamiento como recurso estratégico en cantidad y calidad suficiente para satisfacer la conservación de los sistemas de vida, las necesidades domésticas de las personas y los procesos productivos (Gaceta Oficial del Estado Plurinacional de Bolivia, 2012).

En este estudio se expresan ambas formas de reconocer el derecho humano al agua por las comunidades rurales ubicadas en una condición de estrés hídrica. No obstante, se analiza con el paradigma del Estado.

\section{Materiales y métodos}

\section{Características de la región de estudio: la mixteca baja poblana}


Tecnología y

Ciencias $\approx$ Agua
2020, Instituto Mexicano de Tecnología del Agua

Open Access bajo la licencia CC BY-NC-SA 4.0

(https://creativecommons.org/licenses/by-nc-sa/4.0/)

El estudio se realizó en 30 comunidades de nueve municipios de la región Mixteca mixteca baja, al sur del estado de Puebla, México: Tehuitzingo (Los Hornos de Zaragoza, Cuaulutla, Tecolutla, Tuzantlán y Atopoltitlán); Ahuehuetitla (Guadalupe Alchipini, Piedra Blanca y San Vicente El Peñón); Chinantla (San Miguel Buenavista, Cuatecontla y Amatepetlán); San Jerónimo Xayacatlán (Cañada Estaca, El Cuajilote y Gabino Barreda); San Pablo Anicano (San Miguel Tulapa, El Pedregoso y Francisco González Bocanegra); Tecomatlán (Mixquiapan, Xantoxtla, Tempexquixtle y Tezoquipan); Chila de la Sal (San Pedro Ocotlán); Tulcingo de Valle (La Ciénega, Guadalupe Tulcingo, Aguacatitlán y Francisco Villa), y Piaxtla (Loma Bonita, Yetla, Santa María y Atempa) (Figura 1). 
Tecnología y

\section{Ciencias $\stackrel{\varpi}{\triangleleft}$ Agua}

2020, Instituto Mexicano de Tecnología del Agua

Open Access bajo la licencia CC BY-NC-SA 4.0

(https://creativecommons.org/licenses/by-nc-sa/4.0/)

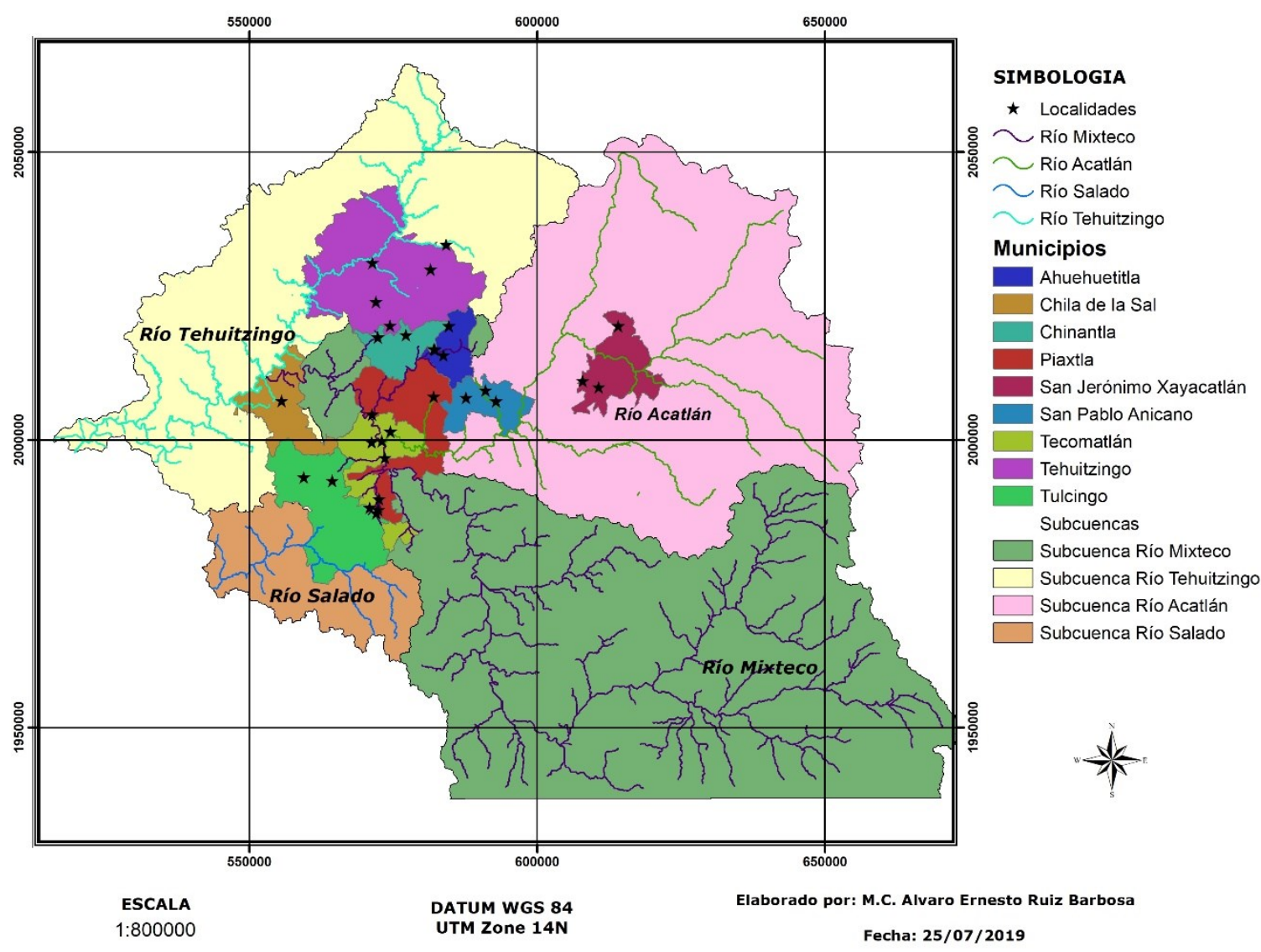

Figura 1. Localización de las subcuencas, principales ríos, municipios y comunidades de la zona de estudio en la mixteca baja poblana. Fuente: elaboración de Álvaro Ernesto Ruiz-Barbosa, con datos vectoriales del Instituto Nacional de Estadística y Geografía (INEGI, 2015).

De acuerdo con el Instituto Nacional para el Federalismo y el Desarrollo Municipal (Inafed, 2010), el área de estudio pertenece a la región mixteca baja del estado de Puebla; comprende una superficie de $1677.6 \mathrm{~km}^{2}$. Se localiza entre los paralelos $17^{\circ} 06^{\prime}$ y $18^{\circ} 30^{\prime}$ de latitud norte, y $97^{\circ} 50^{\prime}$ y $98^{\circ} 33^{\prime}$ de longitud oeste. Presenta tres tipos de 
Tecnología y

Ciencias $₫$ Agua
2020, Instituto Mexicano de Tecnología del Agua

Open Access bajo la licencia CC BY-NC-SA 4.0

(https://creativecommons.org/licenses/by-nc-sa/4.0/)

climas: el $\mathrm{AwO}(\mathrm{w})$ cálido subhúmedo con lluvias en verano; el $\left(B S 1\left(h^{\prime}\right) w(w)\right.$ semiseco, muy cálido y cálido (BS1( $\left.h^{\prime}\right) w(w)$, y el $\mathrm{A}(\mathrm{C}) \mathrm{w0}(\mathrm{w})$ semicálido subhúmedo con lluvias en verano. La altura sobre el nivel del mar fluctúa entre 700 y 1200 metros; precipitaciones entre 600 y $1000 \mathrm{~mm}$; temperaturas entre 20 y $26^{\circ} \mathrm{C}$, y suelos leptosoles, regosoles, phaeozem y vertisoles (INEGI, 2010).

En los nueve municipios estudiados se reportó para 2010 una población de 43622 habitantes (3.7 integrantes); 3210 hogares tenían jefatura femenina (INEGI, 2011).

\section{Técnicas de investigación}

Para la generación de datos se aplicaron las siguientes técnicas de investigación:

a) Encuesta, se aplicó a 221 familias beneficiarias con una cisterna de ferrocemento con el proyecto estratégico de seguridad alimentaria (PESA), de un total de 521. Para determinar el tamaño de muestra se utilizó el muestreo simple aleatorio sin reemplazo, y para la identificación de sus elementos se utilizaron procesos aleatorios. El análisis se presenta en la Ecuación (1): 
Tecnología y

Ciencias $₫$ Agua
2020, Instituto Mexicano de Tecnología del Agua

Open Access bajo la licencia CC BY-NC-SA 4.0

(https://creativecommons.org/licenses/by-nc-sa/4.0/)

$n=\frac{N Z_{\propto / 2}^{2} p n q n}{N d^{2}+Z_{\propto / 2}^{2} p n \quad q n}$

Donde:

$n=$ tamaño de muestra.

$N=$ tamaño de la población $=521$.

$d=$ precisión 0.05 .

$Z_{\mathrm{a} / 2}=$ confiabilidad 1.96

$p n=0.5 ; q n=0.5($ varianza $)$.

Resultado de $n=221$.

Para acopiar información de campo se aplicó un cuestionario a los jefes o jefas de familia de los 221 casos que resultaron del proceso aleatorio. El cuestionario consideró preguntas sobre dos momentos del entorno del agua en el hogar: a) contexto antes de introducir la innovación (antes de construir la cisterna de ferrocemento), y b) escenario después de construir la cisterna de ferrocemento, con el apoyo del proyecto estratégico de seguridad alimentaria. Para estimar el volumen de agua en cada hogar para ambos contextos (antes y después de la cisterna de ferrocemento), se consideraron la Ecuación (2) y la Ecuación (3):

a) Contexto antes de la cisterna: 
Tecnología y

Ciencias $₫$ Agua
2020, Instituto Mexicano de Tecnología del Agua

Open Access bajo la licencia CC BY-NC-SA 4.0

(https://creativecommons.org/licenses/by-nc-sa/4.0/)

$V T A D H=A A A+A A B+A A C+A C C C+A C G$

b) Escenario después de la cisterna:

$V T A D H=A A A+A A B+A A C+A C C C+A C G+A C L L$

Donde VTADH es el volumen total de agua disponible en el hogar; $A A A$, agua acarreada a pie; $A A B$, agua acarreada en burro; $A A C$, agua acarreada en camioneta; $A C C C$, agua comprada de camión cisterna; $A C G$, agua comprada de garrafón, y $A C L L$, agua cosechada de la lluvia.

Se recogió información sobre el acceso y volúmenes de agua de uso doméstico disponibles por familia a través del acarreo a pie, en burro, en camioneta y la compra del servicio del camión cisterna (camión pipa), así como la compra en garrafón. Respecto al agua de la red pública (agua entubada), sólo se indagó sobre la periodicidad.

b) Medición directa. Para generar información precisa de las cisternas de ferrocemento y conocer la capacidad del volumen de agua, se realizaron mediciones directas a 221 cisternas sobre los siguientes indicadores: diámetro, altura y longitud (profundidad). Para calcular el volumen se utilizó la Ecuación (4):

$V c=n * r^{2} * h$ 
Tecnología y

Ciencias $\approx$ Agua
2020, Instituto Mexicano de Tecnología del Agua

Open Access bajo la licencia CC BY-NC-SA 4.0

(https://creativecommons.org/licenses/by-nc-sa/4.0/)

Donde $V c$ es volumen del cilindro; $\Pi$, una constante $(3.14) ; r$, radio, y $h$ es la altura.

c) Observación participante. El investigador participó en todo el proceso de planeación, ejecución y evaluación del proyecto. Esta forma de relación directa permitió conocer y registrar la situación antes y después de la construcción y el uso de la cisterna de ferrocemento (innovación) en el hogar. Se realizaron recorridos por el territorio, reuniones de análisis y planeación, talleres de capacitación y entrevistas, con el objeto de conocer el problema de escasez de agua, las fuentes de abastecimiento, las condiciones del territorio, los utensilios, las obras de almacenamiento y las formas de apropiación del agua.

\section{Análisis de la información}

La información acopiada a través del cuestionario y de la medición directa se organizó en hojas de Excel para su posterior análisis en el software Statistical Package for the Social Sciences (SPSS). La información resultante de la observación participante se registró en libretas de campo y permitió complementar los datos. 
Tecnología y

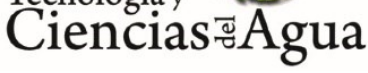

2020, Instituto Mexicano de Tecnología del Agua

Open Access bajo la licencia CC BY-NC-SA 4.0

(https://creativecommons.org/licenses/by-nc-sa/4.0/)

\section{Resultados}

\section{El agua en el contexto de las comunidades de estudio}

El área de estudio pertenece a la Región Hidrológica Administrativa IV Balsas (RHA IV Balsas), que coincide con la Región Hidrológica (RH) 18 Balsas (Conagua \& Semarnat, 2012). La mayor parte de la superficie forma parte de la cuenca del río Atoyac y una menor parte del río Tlapaneco, dentro de la subcuenca de los ríos Mixteco, Acatlán, AtoyacTehuitzingo y Salado. Existe un cuerpo de agua perenne llamado Boqueroncitos. Las corrientes de agua perennes que fluyen por el territorio son los ríos Atoyac, Mixteco, Acatlán y Tecoloyan, y los intermitentes: El Chilsolote, Laguna Seca, La Trompeta, Tizaac, Valiente, Paredón, Tulapa y El Chahuate (INEGI, 2010).

En el territorio existen escasas fuentes de agua y precipitaciones muy erráticas, que no sólo afectan la producción agrícola y pecuaria, sino la satisfacción de las necesidades de agua para consumo humano, 
Tecnología y

Ciencias $\approx$ Agua
2020, Instituto Mexicano de Tecnología del Agua

Open Access bajo la licencia CC BY-NC-SA 4.0

(https://creativecommons.org/licenses/by-nc-sa/4.0/)

higiene personal y diferentes actividades del hogar (lavar ropa y trastes, preparar alimentos y limpiar la casa).

EI INEGI (2011) reportó para 2010 que de los 11380 hogares en los nueve municipios de estudio sólo $60.2 \%$ disponía de agua de la red pública en el ámbito de la vivienda. La situación de los municipios de Tehuitzingo y Chila de la Sal se tornó más grave, pues menos de la mitad de la población disponía de agua de la red púbica. Sin embargo, ninguno de los municipios disponía de agua en todos los hogares (Figura 2).

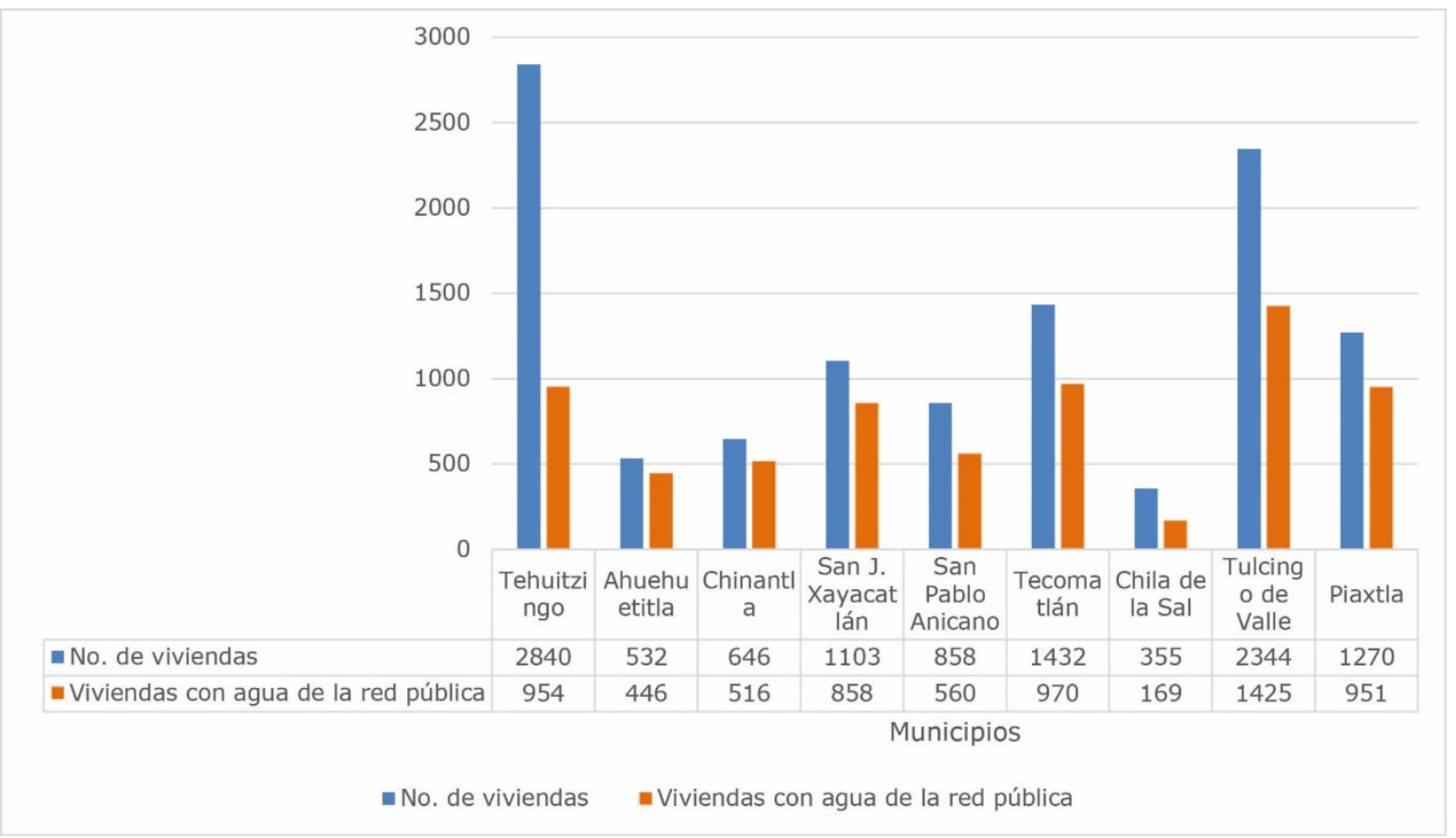

Figura 2. Disponibilidad de agua de la red pública en el ámbito de la vivienda en 2010, en nueve municipios de la mixteca baja poblana. Fuente: elaboración propia con datos del Instituto Nacional de Estadística y Geografía (INEGI, 2011). México en cifras. 
Tecnología y

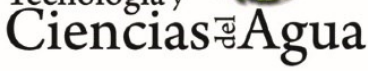

2020, Instituto Mexicano de Tecnología del Agua

Open Access bajo la licencia CC BY-NC-SA 4.0

(https://creativecommons.org/licenses/by-nc-sa/4.0/)

Un estudio más reciente realizado en las 30 comunidades confirma que $40.3 \%$ de las familias carece de agua entubada, por lo que $76.5 \%$ acarrea agua a pie, en burro y en camioneta, y compra agua del servicio de camión cisterna y de garrafón (Ocampo \& Villarreal, 2014).

\section{Cambios y aportaciones de la innovación social al derecho humano al agua}

\section{Cambios derivados con la innovación social}

Los resultados (Tabla 1) muestran que la innovación (cisterna de ferrocemento) aportó beneficios sociales y económicos a las familias de la mixteca en diferentes aspectos, con base en los factores pactados en la observación general núm. 15 (2002) del derecho al agua (artículos 11 y 12 del Pacto Internacional de Derechos Económicos, Sociales y Culturales), que considera los siguientes factores que se aplican en cualquier situación (ONU, 2002): 
Tecnología y

\section{Ciencias $\approx$ Agua}

2020, Instituto Mexicano de Tecnología del Agua

Open Access bajo la licencia CC BY-NC-SA 4.0

(https://creativecommons.org/licenses/by-nc-sa/4.0/)

Tabla 1. Situación de las familias antes y después de instalar la innovación (cisterna de ferrocemento), con base en la observación general número 15 de la Organización de las Naciones Unidas (ONU), en la mixteca baja poblana.

\begin{tabular}{|c|c|c|c|c|c|}
\hline $\begin{array}{l}\text { Observación } \\
\text { general número } \\
15 \text { de la ONU }\end{array}$ & Condición & Indicador & $\begin{array}{c}\text { Condición } \\
\text { para el } \\
\text { óptimo } \\
(100 \%)\end{array}$ & $\begin{array}{c}\text { Situación } \\
\text { antes de la } \\
\text { innovación }\end{array}$ & $\begin{array}{c}\text { Situación } \\
\text { después de } \\
\text { la } \\
\text { innovación }\end{array}$ \\
\hline \multirow[t]{3}{*}{$\begin{array}{l}\text { Disponibilidad } \\
\text { (Abastecimiento) }\end{array}$} & $\begin{array}{l}\text { Entre } 50 \text { y } 100 \\
\text { litros/persona/día }{ }^{1} \\
\text { (OMS, en ONU, } \\
\text { 2010) }\end{array}$ & $\begin{array}{l}\text { Porcentaje de hogares } \\
\text { que disponen entre } 50 \\
\text { y } 100 \\
\text { litros/persona/día }\end{array}$ & $100 \%$ & $97.1 \%$ & $100 \%$ \\
\hline & & $\begin{array}{l}\text { Capacidad de } \\
\text { almacenamiento por } \\
\text { hogar (litros) }\end{array}$ & $\begin{array}{c}30000 \\
\text { litros } \\
\text { (estimado } \\
\text { para la } \\
\text { región en la } \\
\text { época } \\
\text { seca) }\end{array}$ & $\begin{array}{c}5500 \\
(18.3 \%)\end{array}$ & $\begin{array}{c}18953 \\
(63.2 \%)\end{array}$ \\
\hline & & $\begin{array}{l}\text { No. de días que } \\
\text { alcanza el agua } \\
\text { almacenada para los } \\
\text { usos del hogar }\end{array}$ & 60 días & $\begin{array}{c}13.8 \\
(23 \%)\end{array}$ & $\begin{array}{c}47.4 \\
(79 \%)\end{array}$ \\
\hline \multirow[t]{3}{*}{ Calidad } & $\begin{array}{l}\text { Agua salubre: color, } \\
\text { olor y sabor } \\
\text { aceptable (ONU, } \\
2002 \text { ) }\end{array}$ & $\begin{array}{l}\text { No. de familias que } \\
\text { usan el agua de la } \\
\text { cisterna para beber }\end{array}$ & 221 & 0 & $\begin{array}{c}59 \\
(26.7 \%)\end{array}$ \\
\hline & & $\begin{array}{l}\text { No. de familias que } \\
\text { usan el agua de la } \\
\text { cisterna para beber sin } \\
\text { ningún tratamiento }\end{array}$ & 0 & 0 & $\begin{array}{c}24 \\
(10.9 \%)\end{array}$ \\
\hline & & $\begin{array}{l}\text { No. de familias que } \\
\text { usan el agua de la } \\
\text { cisterna para beber }\end{array}$ & 221 & 0 & $\begin{array}{c}35 \\
(15.8 \%)\end{array}$ \\
\hline
\end{tabular}




\section{0, Instituto Mexicano de Tecnología del Agua}

Tecnología y

Ciencias $₫$ Agua
Open Access bajo la licencia CC BY-NC-SA 4.0

(https://creativecommons.org/licenses/by-nc-sa/4.0/)

\begin{tabular}{|c|c|c|c|c|c|}
\hline & & $\begin{array}{l}\text { con algún tratamiento: } \\
\text { hervir, clorar, ambos, } \\
\text { colar }\end{array}$ & & & \\
\hline \multirow[t]{6}{*}{$\begin{array}{l}\text { Accesibilidad } \\
\text { Física }\end{array}$} & $\begin{array}{l}\text { La fuente de agua } \\
\text { debe encontrarse a } \\
\text { menos de } 1000 \\
\text { metros del hogar } \\
\text { (WHO, 2003) }\end{array}$ & $\begin{array}{l}\text { \% de familias que } \\
\text { recorren más de } \\
1000 \text { metros }\end{array}$ & $0 \%$ & $31.5 \%$ & $28 \%$ \\
\hline & $\begin{array}{l}\text { El tiempo de } \\
\text { desplazamiento } \\
\text { para la recogida no } \\
\text { debería superar los } \\
30 \text { minutos (WHO, } \\
2003 \text { ) }\end{array}$ & $\begin{array}{l}\text { \% de familias que se } \\
\text { desplazan más de } 30 \\
\text { minutos }\end{array}$ & $0 \%$ & $20.4 \%$ & $19 \%$ \\
\hline & & $\begin{array}{l}\text { Tiempo dedicado por } \\
\text { día por la familia al } \\
\text { acarreo del agua } \\
\text { (minutos/día/familia) }\end{array}$ & $\begin{array}{l}30 \text { o menos } \\
\text { minutos }\end{array}$ & $\begin{array}{c}125 \\
(208.3 \%) \\
4.2 \text { veces } \\
\text { más }\end{array}$ & $\begin{array}{c}95 \\
(158.3 \%) \\
3.2 \text { veces } \\
\text { más }\end{array}$ \\
\hline & & $\begin{array}{l}\text { Número de familias } \\
\text { que no acarrean agua }\end{array}$ & 221 & $\begin{array}{c}52 \\
(23.5 \%)\end{array}$ & $\begin{array}{c}131 \\
(59.3 \%)\end{array}$ \\
\hline & & $\begin{array}{l}\text { Litros de agua } \\
\text { acarreados y/o } \\
\text { comprados por familia } \\
\text { por todos los medios } \\
\text { por día (l/fam/día) }\end{array}$ & $\begin{array}{l}14.4 \text { litros } \\
\text { (garrafón) }\end{array}$ & 363.6 & 228.2 \\
\hline & & $\begin{array}{l}\text { Número de personas } \\
\text { de la familia que no } \\
\text { deberían dedicarse al } \\
\text { acarreo de agua por } \\
\text { día }\end{array}$ & 0 & 2 & 2 \\
\hline $\begin{array}{l}\text { Accesibilidad } \\
\text { Económica }\end{array}$ & $\begin{array}{l}\text { El costo del agua no } \\
\text { debería superar el } \\
3 \% \text { de los ingresos } \\
\text { del hogar }{ }^{2} \text { (PNUD, } \\
\text { en ONU \& OMS, }\end{array}$ & $\begin{array}{l}\text { Costo por acarreo y } \\
\text { compra de agua } \\
\text { anualmente } \\
\text { (\$/año/familia) }\end{array}$ & $\begin{array}{c}\text { Igual o } \\
\text { menor a } \$ 1 \\
240.92 \\
\text { (Ingreso } \\
\text { promedio }\end{array}$ & 15701.7 & 11151.7 \\
\hline
\end{tabular}


2020, Instituto Mexicano de Tecnología del Agua

Tecnología y

Ciencias Agua
Open Access bajo la licencia CC BY-NC-SA 4.0

(https://creativecommons.org/licenses/by-nc-sa/4.0/)

\begin{tabular}{|c|c|c|c|c|c|}
\hline & 2011) & & $\begin{array}{c}\text { anual } \$ 41 \\
364.0)\end{array}$ & & \\
\hline \multirow[t]{3}{*}{ No discriminación } & $\begin{array}{l}\text { El agua, los } \\
\text { servicios y las } \\
\text { instalaciones deben } \\
\text { estar accesibles a } \\
\text { toda la población } \\
\text { (ONU, 2002) }\end{array}$ & $\begin{array}{l}\text { Número de familias } \\
\text { que dispone del } \\
\text { servicio de agua de la } \\
\text { red pública }\end{array}$ & 221 & $\begin{array}{c}132 \\
(59.7 \%)\end{array}$ & $\begin{array}{c}144 \\
(65.2 \%)\end{array}$ \\
\hline & & $\begin{array}{l}\text { Número de familias } \\
\text { que dispone del } \\
\text { servicio de agua de la } \\
\text { red pública todo el año }\end{array}$ & 221 & $\begin{array}{c}119 \\
(53.8 \%)\end{array}$ & $\begin{array}{c}131 \\
(59.3 \%)\end{array}$ \\
\hline & & $\begin{array}{l}\text { Número de familias } \\
\text { que dispone de una } \\
\text { cisterna de } \\
\text { ferrocemento }\end{array}$ & 221 & 0 & $\begin{array}{c}221 \\
(100 \%)\end{array}$ \\
\hline $\begin{array}{l}\text { Acceso a la } \\
\text { información }\end{array}$ & $\begin{array}{l}\text { Toda la población } \\
\text { tiene derecho a } \\
\text { recibir información } \\
\text { (ONU, 2002) }\end{array}$ & $\begin{array}{l}\text { Número de familias } \\
\text { que recibieron } \\
\text { información de la } \\
\text { cisterna a través del } \\
\text { pesa }\end{array}$ & 221 & 0 & $\begin{array}{c}221 \\
(100 \%)\end{array}$ \\
\hline
\end{tabular}

${ }^{1}$ El acceso óptimo es entre 100 y 200 litros por persona por día (WHO, 2003).

2 Los gobiernos y los organismos internacionales han establecido a menudo un umbral de asequibilidad que oscila entre el $2 \%$ y el $6 \%$ del gasto total (OMS \& UNICEF, 2017).

Fuente: elaboración propia con información de campo y de ONU $(2002,2010)$; WHO (2003); ONU \& OMS, 2011.

I. La disponibilidad. Cada persona debe tener un suministro de agua continuo y suficiente para los usos personales y domésticos, que considera consumo, saneamiento, preparación de alimentos, e higiene personal y doméstica. Las necesidades de cada persona pueden variar y 
Tecnología y

Ciencias $₫$ Agua
2020, Instituto Mexicano de Tecnología del Agua

Open Access bajo la licencia CC BY-NC-SA 4.0

(https://creativecommons.org/licenses/by-nc-sa/4.0/)

necesitar más agua por razones de salud, clima y condiciones de trabajo.

La Organización Mundial de la Salud establece que la disponibilidad de agua debe ser entre 50 y 100 litros por persona al día (ONU, 2010). Otros estándares consideran que 50 litros por persona por día de agua limpia son suficientes para las necesidades humanas (Gleick, 1996).

Para el caso en estudio, $97.1 \%$ de los hogares cumplía esta condición antes de disponer de la cisterna de ferrocemento, situación que cambió al 100\% con la innovación. Sin embargo, por las condiciones ambientales de la región, el volumen debería ser mayor. Un acceso óptimo debe ser entre 100 y 200 litros por persona por día (WHO, 2003).

La capacidad de almacenamiento aumentó en un $244.6 \%$; antes de instalar la cisterna cada familia disponía en promedio de 5500 litros. Con la innovación, se sumaron en promedio 13453 litros, aumentando a 18953 litros por familia, situación que propició almacenar mayor volumen de agua de lluvia y de camión cisterna, y aumentar en $128.6 \%$ el número de familias que compraron agua de camión cisterna en época seca en comparación a la situación anterior.

Estimaciones realizadas con las familias, son necesarios 30000 litros para la época más seca (marzo, abril y mayo); antes de la cisterna la capacidad de almacenamiento era de $18.3 \%$, con la innovación tienen una capacidad de $63.2 \%$, es decir, aún es insuficiente, se necesitan cisternas de mayor volumen u otra de la misma capacidad. 
Tecnología y

Ciencias $\approx$ Agua
2020, Instituto Mexicano de Tecnología del Agua

Open Access bajo la licencia CC BY-NC-SA 4.0

(https://creativecommons.org/licenses/by-nc-sa/4.0/)

Respecto al número de días que alcanza el agua almacenada (volumen de todos los depósitos), resultó que sin cisterna el volumen de agua alcanzaba para 13.8 días y con cisterna 47.4 días; es decir, se incrementó $79.0 \%$.

II. La calidad. El agua para cada uso personal o doméstico debe ser salubre, y estar libre de microorganismos o sustancias químicas o radiactivas que amenacen la salud de las personas, y tener un color, un olor y un sabor admisibles (ONU, 2002). Para el caso en estudio no se realizaron análisis de agua, solo se consideró la opinión sobre el tratamiento que proporcionan al agua (captada en la cisterna) que usan para ingesta.

Las opiniones muestran que el $26.7 \%$ de las familias usan el agua de la cisterna para tomar, $10.9 \%$ lo usan sin ningún tratamiento y $15.8 \%$ la hierven, la cloran, hacen ambos tratamientos o la filtran. Un estudio realizado por López, Ocampo y Tornero (2015) en municipios vecinos, para determinar si el agua de lluvia almacenada en cisternas de ferrocemento cumple los criterios de calidad para consumo humano de acuerdo a la NOM-127-SSA1-1994, mostró que los componentes fisicoquímicos están dentro de los parámetros para que el agua pueda ser utilizada para consumo humano y otros usos. Sin embargo, es necesario realizar estudios microbiológicos.

III. La accesibilidad presenta cuatro dimensiones: 
Tecnología y

Ciencias
2020, Instituto Mexicano de Tecnología del Agua

Open Access bajo la licencia CC BY-NC-SA 4.0

(https://creativecommons.org/licenses/by-nc-sa/4.0/)

a) Accesibilidad física. Toda la población debe tener acceso al agua, a las instalaciones y a los servicios de agua. Cada hogar y espacio educativo o de trabajo debe tener acceso a agua suficiente, salubre y aceptable, y tanto las instalaciones como el servicio debe ser de calidad y adecuados a las condiciones de la población (ONU, 2002).

Las familias deben de recorrer menos de 1000 metros y el tiempo para la recogida de agua no debe ser mayor a los 30 minutos (WHO, 2003). Antes de la cisterna $31.5 \%$ de las familias recorrían más de 1 000 metros y con la innovación el número de familias disminuyó a $28.0 \%$. En el mismo sentido el número de familias que se desplazan más de 30 minutos disminuyó de 20.4 a 19.0\%. Disponer de un abastecimiento regular de agua en la vivienda, evitaría que mujeres y niños dedicaran tiempo y energía física para ir a recoger agua de fuentes distantes (ONU \& OMS, 2011).

En relación al tiempo dedicado al acarreo de agua por día por familia disminuyó en $\mathbf{2 4 . 0 \%}$. Antes cada persona utilizaba en promedio 25 minutos por viaje, realizaba 2.5 viajes, y se empleaban 2 personas, resultando dos horas y 5 minutos por familia; posteriormente cada persona utilizó en promedio 25 minutos por viaje, realiza 1.9 viajes, y se emplean 2 personas, resultando una hora y 35 minutos por familia al día. Actualmente cada familia dispone de media hora más al día para realizar otras actividades.

El número de familias que dejaron de acarrear agua aumentó de 23.5 a 59.3\% antes y después de disponer de la cisterna, respectivamente; es decir, $35.7 \%$ dejaron de acarrear agua dedicando el tiempo a otras actividades. Considerando que las familias no debería 
Tecnología y

Ciencias $\approx$ Agua
2020, Instituto Mexicano de Tecnología del Agua

Open Access bajo la licencia CC BY-NC-SA 4.0

(https://creativecommons.org/licenses/by-nc-sa/4.0/)

acarrear agua y solo comprar 14.4 I de garrafón para beber y cocinar, los datos muestran que los litros acarreados y/o comprados por familia por día disminuyó de 363.6 I a 228.2 I después de la cisterna. A pesar de lo anterior, el número de personas por familia dedicadas a acarrear agua no sufrió modificación en las familias que continuaron el acarreo; es decir, dos personas por familia continuaron acarreando agua.

b) Accesibilidad económica. Toda persona debe tener acceso al agua, al servicio y a las instalaciones. Los costos y cargos directos e indirectos relacionados con el abastecimiento de agua deben ser accesibles y no deben poner en riesgo otros derechos humanos (ONU, 2002).

Al respecto las familias se favorecieron al disminuir en un $29 \%$ el monto anual por pago de agua acarreada y comprada de camión cisterna y garrafón. Actualmente el ahorro es de \$4 550.00 anuales. Miranda-Trejo (2013) reporta gastos por $\$ 3600.00$ tan solo por compra de agua de camión cisterna en el municipio de Tepexi de Rodríguez, Puebla, también dentro de la mixteca.

c) No discriminación. Ningún grupo social incluyendo los más vulnerables y marginados debe ser discriminado; todos tienen derecho al agua y los servicios e instalaciones de agua (ONU, 2002).

En este sentido, en una comunidad se construyó un depósito comunitario de $40000 \mathrm{I}$, abastecido de un pozo de uso comunitario y conectado a una red de abastecimiento que alimenta a las 30 cisternas familiares de 18000 I, aumentando de 59.7 a $65.2 \%$ el servicio de la red pública, y la disponibilidad de agua todo el año de 53.8 a 59.3\% antes y después de construida las cisternas, respectivamente. Por otro 
Tecnología y

Ciencias Agua
2020, Instituto Mexicano de Tecnología del Agua

Open Access bajo la licencia CC BY-NC-SA 4.0

(https://creativecommons.org/licenses/by-nc-sa/4.0/)

lado, el $100 \%$ de las familias participantes instaló una cisterna de ferrocemento que antes no tenía.

d) Acceso a la información. Toda la población tiene derecho a la información sobre los aspectos del agua (ONU, 2002).

En este sentido al $100 \%$ de las comunidades y familias seleccionadas para participar en el programa, se les compartió información sobre el programa de seguridad alimentaria y en específico sobre las cisternas de ferrocemento. Sin embargo, por criterios de selección no todas las familias resultaron beneficiadas.

\section{Discusión}

La concepción del Estado sobre el derecho al agua proyecta satisfacer necesidades de consumo, cocina, higiene personal y doméstico para evitar la muerte, reducir riesgos de enfermedades y para una vida digna (ONU, 2002). Desde un enfoque social destaca el acceso universal al agua suficiente para las necesidades básicas como prioridad absoluta (Langford \& Khalfan, 2006) y considera el derecho al agua vinculada a la vida cultural de los pueblos para gozar de una vida digna (Salmón, 2012). 
Tecnología y

Ciencias 종ua
2020, Instituto Mexicano de Tecnología del Agua

Open Access bajo la licencia CC BY-NC-SA 4.0

(https://creativecommons.org/licenses/by-nc-sa/4.0/)

En este proyecto se articularon las dos concepciones; por un lado, la participación del Estado en la gestión de un proyecto para cosechar agua de lluvia, facilitando tecnología y conocimientos, y por otro, la organización, participación y conocimientos de las comunidades para construir las cisternas de ferrocemento, como una innovación social en la región.

Considerando los alcances de este estudio, fue posible evaluar los aportes de la innovación social a los hogares y los avances en materia de derecho humano al agua. Lo primordial es que la innovación solucione problemas sociales relevantes y satisfaga necesidades de la población mostrando sus bondades en relación a otras soluciones (Van der Have \& Rubalcaba, 2016; Álvarez-González et al., 2017).

Con base en los factores pactados por la ONU en la observación general No. 15 (2002) (ONU, 2002), la innovación benefició a las familias, contribuyendo al derecho humano al agua.

De las 221 familias entrevistadas, el 100\% opinó haber recibido diferentes beneficios con la cisterna de ferrocemento. $61.2 \%$ opinó que los tres principales fueron: a) disponer de un depósito con mayor capacidad en relación al conjunto de depósitos que tenía antes de la cisterna; b) disponer de agua para regar plantas del huerto $y, c$ ) disminuir el acarreo de agua en las diferentes formas que lo hacía. Otros beneficios se refirieron a la disponibilidad de agua para la época más seca del año (marzo a mayo), disminuir el gasto por compra de agua, acceder al agua para diversos usos del hogar y para abrevar a los animales, principalmente caprinos, bovinos, aves de corral y asnos (Figura 3). Pol y Ville (2009) señalan que una innovación para que sea 
Tecnología y

\section{Ciencias $₫$ Agua}

2020, Instituto Mexicano de Tecnología del Agua

Open Access bajo la licencia CC BY-NC-SA 4.0

(https://creativecommons.org/licenses/by-nc-sa/4.0/)

social debe mejorar las condiciones económicas y sociales; es decir, mejorar la calidad de vida. Los resultados revelan esta característica de la cisterna de ferrocemento.

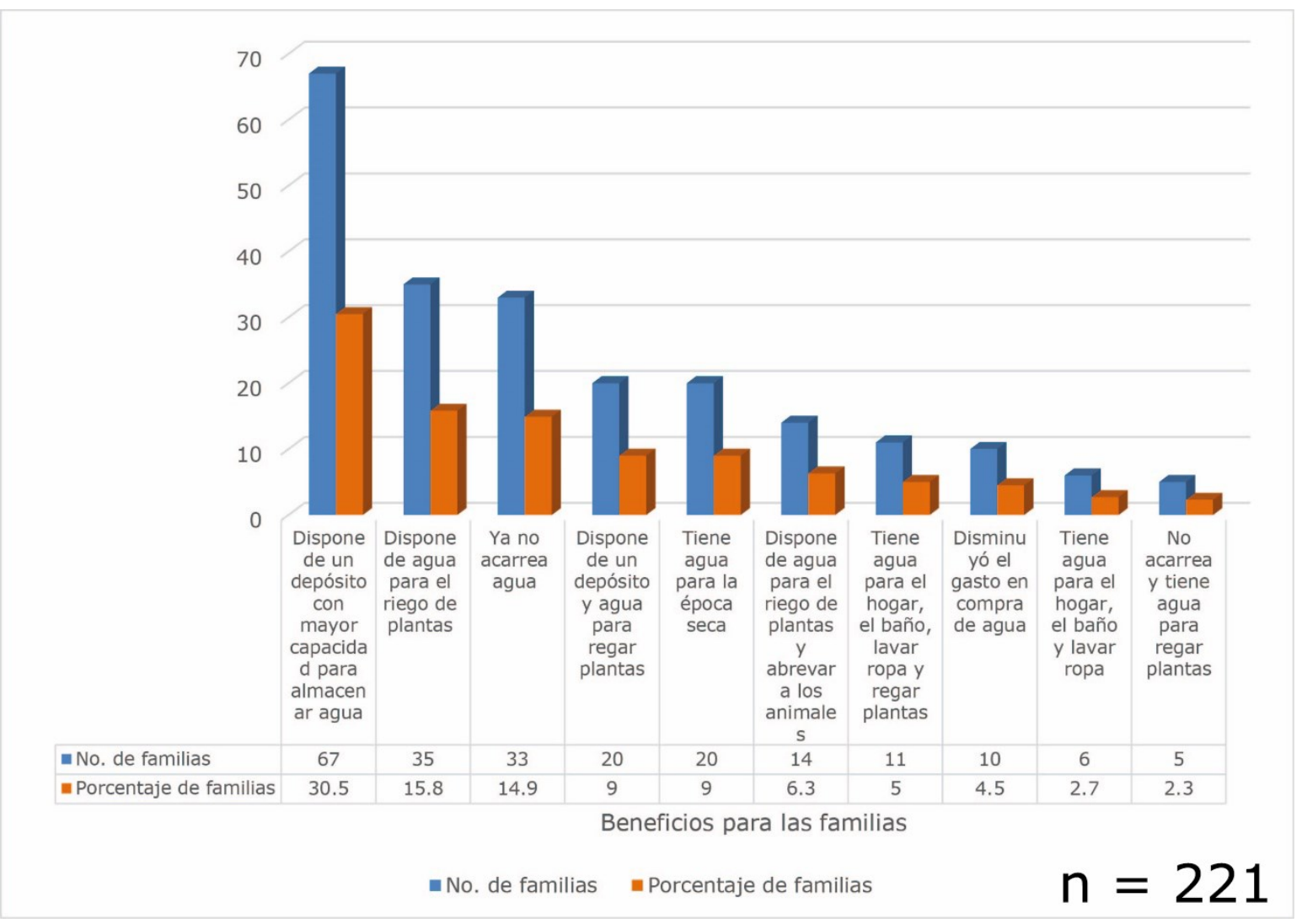

Figura 3. Beneficios de la cisterna de ferrocemento en opinión de las familias (No. y \%). Fuente: elaboración propia con base en información de campo.

Estos resultados coinciden con lo reportado en otros estudios. Contreras, Vásquez, Zapata y Bustos (2011) registraron disminución de carga de trabajo (por acarreo de agua) en las mujeres y disponibilidad 
Tecnología y

Ciencias $₫$ Agua
2020, Instituto Mexicano de Tecnología del Agua

Open Access bajo la licencia CC BY-NC-SA 4.0

(https://creativecommons.org/licenses/by-nc-sa/4.0/)

de agua hasta seis meses, por aumentar la capacidad de captación y almacenamiento de agua de lluvia, en tres comunidades de Querétaro, México.

Por sus beneficios la innovación social se ha promovido por los programas públicos en muchos países. En México, se implementó a través del proyecto estratégico de seguridad alimentaria (PESA), para la cosecha de agua para el hogar saludable y la producción de alimentos. Una evaluación del programa realizada en diez entidades a una muestra de 1078 beneficiarios reportó que la disponibilidad de agua pasó de $28.7 \%$ con acceso temporal a $62.9 \%$ con disponibilidad todo el año; los beneficiarios que almacenaban agua aumentó de $45 \%$ antes del proyecto a 90\% (Sagarpa, 2013). Otro programa semejante se implementó en el semiárido brasileño "Un millón de cisternas" para la captación de agua de lluvia para el consumo humano (PNUD, 2016).

La introducción de la innovación planteó como objetivo cosechar y almacenar agua de lluvia para el hogar saludable; las necesidades obligaron a las familias a utilizar el agua en diferentes actividades en forma combinada, tanto para la higiene y bebida personal, las actividades del hogar (lavado de ropa y trastes, limpieza y preparación de alimentos), el riego de plantas cultivadas en macetas y pequeños espacios y para los animales. $91.9 \%$ de las familias la utilizaron para la producción de alimentos (riego de plantas), 79.2\% para las necesidades del hogar, $75.6 \%$ para la ingesta e higiene personal y $64.8 \%$ para bebida de animales (Figura 4). 
Tecnología y

\section{Ciencias $₫$ Agua}

2020, Instituto Mexicano de Tecnología del Agua

Open Access bajo la licencia CC BY-NC-SA 4.0

(https://creativecommons.org/licenses/by-nc-sa/4.0/)

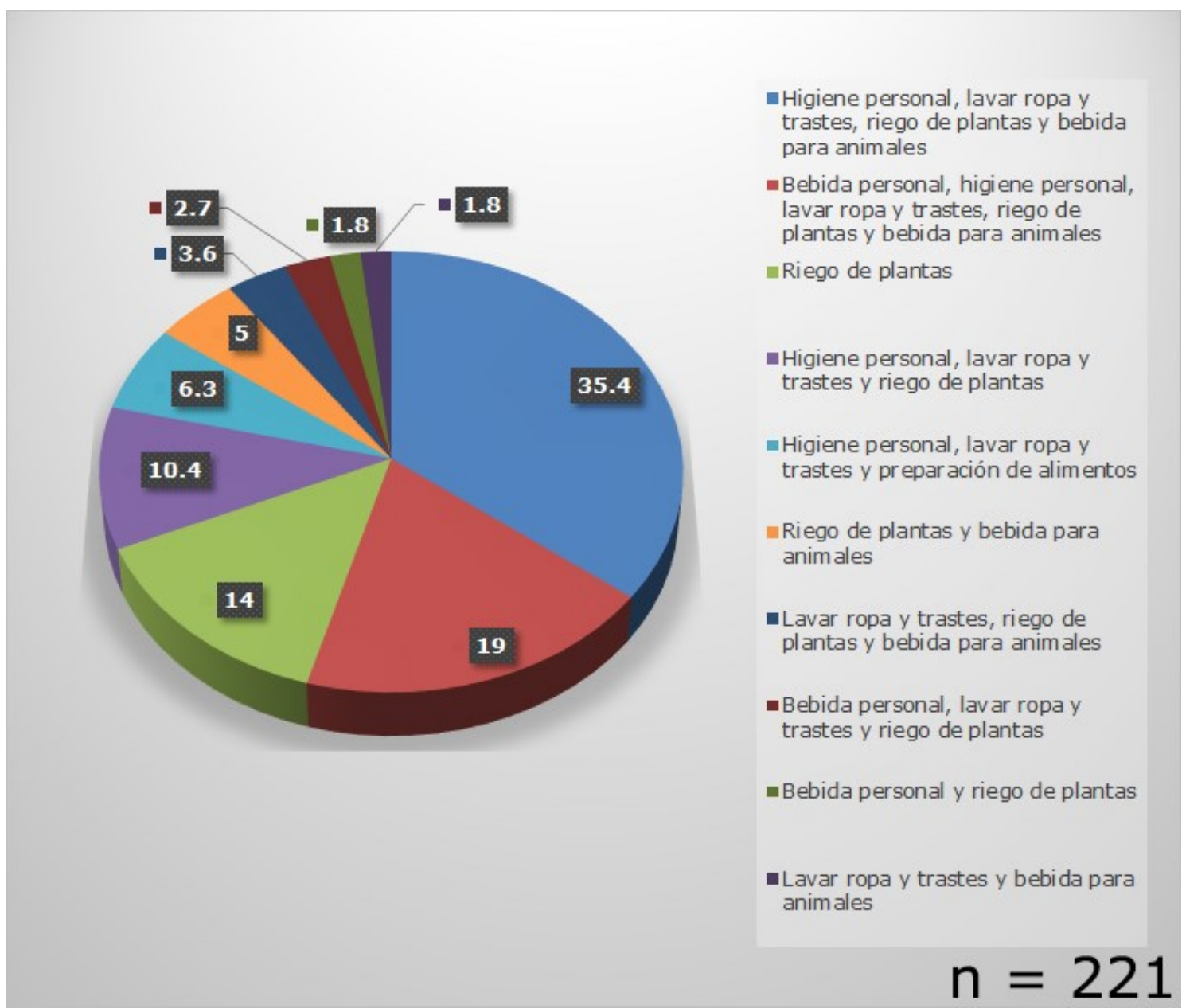

Figura 4. Usos del agua almacenada en cisternas de ferrocemento en la región mixteca baja de Puebla (\% de familias). Fuente: Elaboración propia con base en información de campo.

Mora, Jiménez, Carrasco y Abarca (2016) señalan que el agua almacenada en cisternas de ferrocemento puede ser usada en la producción agrícola, para bebida de animales e incluso humana, sobre todo en periodos de escasez de agua; al ser un sistema cerrado, existe menos riesgo por contaminación de microorganismos. 
Tecnología y

Ciencias $\mathrm{\approx}$ Agua
2020, Instituto Mexicano de Tecnología del Agua

Open Access bajo la licencia CC BY-NC-SA 4.0

(https://creativecommons.org/licenses/by-nc-sa/4.0/)

Además, la innovación provocó cambios en las relaciones sociales de cooperación para resolver problemas relevantes de una necesidad colectiva como lo señala Van der Have y Rubalcaba (2016). La apropiación de la innovación mostró la capacidad de la gente para explorar otro método de captación de agua con beneficios sociales como lo sugiere Smith (2017), donde influyó el uso de metodologías participativas para escuchar a la comunidad sobre sus necesidades, aspiraciones y sus propuestas de solución, permitiendo conocer el sistema de valores, creencias y comportamientos para la toma de decisiones estratégicas de acuerdo a Espiau (2017).

No obstante a los progresos falta mucho por hacer; es primordial reconocer el acceso al agua como un derecho humano, y priorizar políticas y garantizar el acceso a agua limpia y de calidad (Ribeiro, 2018), sobre todo, en condiciones semiáridas como el caso estudiado, con pocas fuentes de agua y precipitaciones bajas e irregulares. Gleick (1996) señala que las condiciones climáticas (entre otras) influyen en la cantidad de agua de uso doméstico necesaria por persona por día, y considera que para comunidades rurales de climas secos debe ser entre 60 y 80 litros per cápita al día. Sin embargo, la WHO (2003) (sin especificar condición climática) recomienda entre 100 y 200 litros por persona por día.

Lo anterior plantea continuar con proyectos más eficaces a partir de esta experiencia. La apropiación de la innovación social fue el resultado de la coparticipación del Estado y de las comunidades que compartieron recursos y trabajo para un mismo objetivo. Estas últimas, basadas en su experiencia en organización comunitaria, en prácticas 
Tecnología y

Ciencias $₫$ Agua
2020, Instituto Mexicano de Tecnología del Agua

Open Access bajo la licencia CC BY-NC-SA 4.0

(https://creativecommons.org/licenses/by-nc-sa/4.0/)

tecnológicas locales para cosechar agua, y en las relaciones de poder construidas en su contexto histórico, ecológico y cultural, aprovecharon los apoyos del Estado, logrando generar una nueva experiencia para afrontar la escasez de agua.

Importante considerar las limitantes del proceso y tratar de cambiarlas. Por parte de los actores externos persisten largos trámites administrativos, gran número de actores institucionales, retraso en la entrega de los materiales de construcción y un excesivo proceso de evaluación. En los actores internos existe desconfianza en las instituciones. Es necesario el trabajo en coparticipación y en una relación de confianza.

\section{Conclusiones}

La introducción de las cisternas de ferrocemento para la cosecha de agua de lluvia como alternativa al déficit de agua en los hogares de la región mixteca resultó ser una innovación social aceptada por las familias. El aumento del volumen hídrico en sus hogares disminuyó la presión sobre el acceso al agua y contribuyó a satisfacer las necesidades personales y domésticas, y en algunos casos, asegurar agua para la producción de plantas a pequeña escala y para los animales de corral. 
Tecnología y

Ciencias $\approx$ Agua
2020, Instituto Mexicano de Tecnología del Agua

Open Access bajo la licencia CC BY-NC-SA 4.0

(https://creativecommons.org/licenses/by-nc-sa/4.0/)

La innovación social generó algunos beneficios que sugieren contribuciones al derecho humano al agua, con base en los factores pactados por la ONU en la observación general núm. 15 del derecho al agua. En el atributo de disponibilidad de agua aumentó la capacidad de almacenamiento $y$, en consecuencia, el volumen per cápita mejoró en todos los hogares, ampliando el periodo de tiempo con agua disponible.

Respecto a accesibilidad física, disminuyó el número de familias que recorren más de 1000 metros y las que se desplazan más de 30 minutos para recoger agua; también se redujo el tiempo dedicado por familia al acarreo, al igual que el número de familias que acarrean agua y el volumen de agua acarreada y/o comprada. En accesibilidad económica, el impacto fue positivo, al reducir el gasto económico por acarreo y compra de agua. La innovación provocó cambios incrementales y transformacionales de la vida de las familias.

Sin embargo, los resultados valorados como positivos por los beneficiarios de las cisternas son insuficientes para resolver el problema de estrés hídrico en los hogares. En tanto las familias continúen acarreando y comprando agua de camión cisterna y no tengan acceso al agua de calidad de una red pública en forma continua, no se cumplirá el derecho humano al agua. El acarreo a pie o en burro en condiciones abruptas (barrancas, pendiente, temperatura, etc.), con alta participación de mujeres y niñas y niños es vulnerar sus derechos a una vida digna.

Por otro lado, la cisterna de ferrocemento como nueva idea asociada con el estrés hídrico, motivó la participación de las familias (hombres, mujeres, jóvenes y niños), quienes asumieron el compromiso 
Tecnología y

Ciencias $₫$ Agua
2020, Instituto Mexicano de Tecnología del Agua

Open Access bajo la licencia CC BY-NC-SA 4.0

(https://creativecommons.org/licenses/by-nc-sa/4.0/)

de autoconstruirlas. Un elemento generador de movilización fue el apoyo del Estado; asistió con materiales de construcción y con la capacitación, favoreciendo la apropiación de la innovación social. En este contexto, las políticas públicas deberían tener una visión de la innovación con efectos sociales, facilitando la participación de los ciudadanos para fomentar el desarrollo social.

Por las condiciones naturales de la mixteca son necesarios proyectos comunitarios y micro regionales para la cosecha, almacenamiento, conservación y manejo sostenible del agua. Ello demanda mayor intervención de los diferentes niveles del gobierno y más participación de la población en procesos de planeación, ejecución y evaluación de los proyectos enfocados al acceso al agua potable.

\section{Referencias}

Alijani, S., \& Wintjes, R. (2017). Interplay of technological and social innovation. SIMPACT Woriking Paper, 2017(3). Gelsenkirchen, Germany: Institute for Work and Technology. Recuperado de http://www.simpact-project.eu/publications/wp/WP_2017-

03_AlijaniWintjes.pdf

Álvarez-González, L. I., García-Rodríguez, N., Sanzo-Perez, M. J., \& Rey-García, M. (2017). Análisis multidimensional del concepto de innovación social en las organizaciones no lucrativas españolas. Evidencias prácticas. Revista Española del Tercer Sector, (36), cuatrimestre II, 23-48. Recuperado de 
Tecnología y

Ciencias $₫$ Agua
2020, Instituto Mexicano de Tecnología del Agua

Open Access bajo la licencia CC BY-NC-SA 4.0

(https://creativecommons.org/licenses/by-nc-sa/4.0/)

https://www.accioncontraelhambre.org/sites/default/files/docume nts/revista_rets_n36.pdf

Amaro, R. M., Morales, S. M. A., \& Villavicencio, C. D. (2011). Problemas relacionados con los indicadores sobre formación de recursos humanos en ciencia y tecnología en México. En: Villavicencio, C. D. H., Martínez, M. A., \& López, De A. P. L. (coords.). Dinámicas institucionales y políticas de innovación en México (pp. 249-271). México, DF, México: Universidad Autónoma Metropolitana-Xochimilco, y Plaza y Valdés S. A. de C. V.

Asamblea Constituyente. (2008). Constitución de la República del Ecuador. Recuperado de https://www.wipo.int/edocs/lexdocs/laws/es/ec/ec030es.pdf

Azar, L. B. A. (2018). Derecho humano de acceso al agua y su relación con la gestión del vital líquido en el sistema jurídico mexicano. En: Chan, S., Ibarra, P. F., \& Medina, A. M. de J. (coords). Bioética y bioderecho. Reflexiones clásicas y nuevos desafíos (pp. 411-438). Ciudad de México, México: Universidad Nacional Autónoma de México.

Boni, A., Belda-Miquel, S., \& Pellicer-Sifres, V. (2018). Innovación transformadora. Propuestas desde la innovación social colectiva para el desarrollo humano. Recerca, revista de pensament $i$ análisi, (23), 67-94. DOI: 10.6035/Recerca.2018.23.4

Conagua \& Semarnat, Comisión Nacional del Agua, Secretaría de Medio Ambiente y Recursos Naturales. (2012). Programa Hídrico Regional Visión 2030. Región Hidrológico-Administrativa IV Balsas. 
Tecnología y

Ciencias $\mathrm{\approx}$ Agua
2020, Instituto Mexicano de Tecnología del Agua

Open Access bajo la licencia CC BY-NC-SA 4.0

(https://creativecommons.org/licenses/by-nc-sa/4.0/)

Ciudad de México, México: Comisión Nacional del Agua y Secretaría de Medio Ambiente y Recursos Naturales.

Contreras, C. E. A., Vásquez, G. V., Zapata, M. E., \& Bustos, C. D. A. (2011). Género y tecnología doméstica. Análisis de la transferencia de un paquete de ecotecnias a mujeres rurales de Querétaro, México. Revista Venezolana de estudios de la mujer, 16(36), 99-116.

Espiau, I. G. (2017). Nuevas tendencias de la innovación social. Revista Española del Tercer Sector, (36), cuatrimestre II, 139-168. Recuperado de https://www.accioncontraelhambre.org/sites/default/files/docume nts/revista_rets_n36.pdf

FAO, Organización de las Naciones Unidas para la Alimentación y la Agricultura. (2015). La FAO y los 17 objetivos del desarrollo sostenible. Roma, Italia: Organización de las Naciones Unidas para la Alimentación y la Agricultura. Recuperado de http://www.fao.org/3/a-i4997s.pdf

Gaceta Oficial del Estado Plurinacional de Bolivia. (2012). Ley No. 300. Ley de 15 de octubre de 2012. Ley Marco de la Madre Tierra y Desarrollo Integral para Vivir Bien. La Paz, Bolivia: Asamblea Legislativa Plurinacional. Recuperado de http://base.socioeco.org/docs/ley_20n_c2_b0_20300_20marco_2 0de_20la_20madre_20tierra.pdf

Gentes, I. G. (2001). Derechos al agua de los pueblos indígenas en América latina. Serie recursos naturales e infraestructura núm. 38. 
Tecnología y

Ciencias
2020, Instituto Mexicano de Tecnología del Agua

Open Access bajo la licencia CC BY-NC-SA 4.0

(https://creativecommons.org/licenses/by-nc-sa/4.0/)

Santiago, Chile: Naciones Unidas, Comisión Económica para América Latina y el Caribe. Recuperado de https://repositorio.cepal.org/bitstream/handle/11362/6394/S0112 1099_es.pdf?sequence $=1$ \&isAllowed $=y$

Gleick, P. H. (1996). Basic water requirements for human activities: Meeting basic needs. Water International, 21(2), 83-92. DOI: 10.1080/02508069608686494.

Huanacuni, M. F. (2010). Buen vivir/vivir bien. Filosofía, políticas, estrategias y experiencias regionales indígenas. Lima, Perú: Coordinadora Andina de Organizaciones Indígenas.

Inafed, Instituto Nacional para el Federalismo y el Desarrollo Municipal. (2010). Ficha básica municipal 2010. México, DF, México: Instituto Nacional para el Federalismo y el Desarrollo Municipal. Recuperado de http://www.snim.rami.gob.mx/index2.html.

INEGI, Instituto Nacional de Estadística y Geografía. (2010). Compendio de información geográfica municipal 2010 (claves geoestadísticas: 21009, 21056, 21059, 21113, 21127, 21139, 21155, 21157 y 21191). Aguascalientes, México: Instituto Nacional de Estadística y Geografía. Recuperado de http://www.inegi.org.mx/geo/contenidos/topografia/compendio.as $\mathrm{px}$

INEGI, Instituto Nacional de Estadística y Geografía. (2011). México en cifras. Información nacional, por entidad federativa y municipios. Aguascalientes, México: Instituto Nacional de Estadística y 
Tecnología y

Ciencias $₫$ Agua
2020, Instituto Mexicano de Tecnología del Agua

Open Access bajo la licencia CC BY-NC-SA 4.0

(https://creativecommons.org/licenses/by-nc-sa/4.0/)

Geografía.

Recuperado

de http://www.beta.inegi.org.mx/app/areasgeograficas/\#

INEGI, Instituto Nacional de Estadística y Geografía. (2015). Datos vectoriales. Aguascalientes, México: Instituto Nacional de Estadística y Geografía.

Langford, M., \& Khalfan, A. (2006). Introducción al agua como derecho humano. En: Esch, S., Delgado, M., Helfrich, S., Salazar, R. H., Torregrosa, M. L., \& Zúñiga, P. T. I. La gota de la vida: hacia una gestión sustentable y democrática del agua (pp. 30-62). México, DF, México: Fundación Heinrich Böll. Recuperado de https://mx.boell.org/sites/default/files/libro_la_gota.pdf

López, T. Z. G., Ocampo, F. I., \& Tornero, C. M. A. (noviembre, 2015). Composición fisicoquímica del agua de lluvia almacenada y posibilidad de uso para consumo humano. En: Villanueva-Jiménez, J. A., \& Jarquín-Gálvez, R. (coords.). $8^{\circ}$ Congreso Nacional de Agricultura Sostenible. Universidad Autónoma de Aguascalientes y Sociedad Mexicana de Agricultura Sostenible A. C., Aguascalientes, México.

Martínez, M. A. (2017). El derecho al agua en el Ecuador. Un análisis desde la ciencia política y el derecho público. Cuenca, Ecuador: Universidad de Cuenca. Recuperado de https://www.researchgate.net/publication/322317326_El_Derecho _al_Agua_en_el_Ecuador_Un_analisis_desde_la_Ciencia_Politica_y _el_Derecho_Publico 
Tecnología y

Ciencias $\approx$ Agua
2020, Instituto Mexicano de Tecnología del Agua

Open Access bajo la licencia CC BY-NC-SA 4.0

(https://creativecommons.org/licenses/by-nc-sa/4.0/)

Miranda-Trejo, M. (2013). Gestión del agua público-urbana en la cabecera municipal de Tepexi de Rodríguez, Puebla (tesis de maestría en ciencias). Colegio de Postgraduados, Campus Puebla, Puebla, México.

Mitre, G. E. (2012). La protección del derecho al agua en el derecho constitucional comparado y su introducción en los criterios de tribunales internacionales de derechos humanos. Pensamiento Jurídico, (35), 231-252. Recuperado de https://es.scribd.com/document/274909056/Derecho-Al-AguaJose-Mitre-Guerra

Mora, L. D., Jiménez, S. N., Carrasco, J. J., \& Abarca, R. P. (2016). Cisternas de ferrocemento: tecnología adecuada para la acumulación de agua de lluvias. En: Carrasco, J. (ed.). Técnicas de captación, acumulación, y aprovechamiento de aguas Iluvias (pp. 74-108). Boletín INIA núm. 321. Rengo, Chile: Instituto de Investigaciones Agropecuarias, Centro Regional Rayentué. Recuperado de http://www.produccionanimal.com.ar/agua_cono_sur_de_america/86-captacion_inia.pdf

Morales, G. A. C. (2008). Innovación social: una realidad emergente en los procesos de desarrollo. Revista de Fomento Social, (251), 411444.

Ocampo, F. I., \& Villarreal, M. L. A. (2014). Recursos hídricos, movilidad social territorial para su aprovechamiento y derecho humano al agua en comunidades de la mixteca baja de Puebla, México. Ambiente y Desarrollo, 18(35), 55-69. DOI: 10.11144/Javeriana.AyD18-35.rhms 
Tecnología y

Ciencias $₫$ Agua
2020, Instituto Mexicano de Tecnología del Agua

Open Access bajo la licencia CC BY-NC-SA 4.0

(https://creativecommons.org/licenses/by-nc-sa/4.0/)

OEA, Organización de los Estados Americanos. (2013). Actas y documentos, volumen I. "Cuadragésimo segundo periodo ordinario de sesiones". Cochabamba, Bolivia: Organización de los Estados Americanos (del 3 al 5 de junio de 2012). Recuperado de http://www.oas.org/es/sla/docs/ag05796s04.pdf

OMS \& UNICEF, Organización Mundial de la Salud y Fondo de las Naciones Unidas para la Infancia. (2017). Progresos en materia de agua potable, saneamiento e higiene. Informe de actualización de 2017 y línea de base de los ODS. Ginebra, Suiza: Organización Mundial de la Salud y Fondo de las Naciones Unidas para la Infancia. Recuperado de https://apps.who.int/iris/bitstream/handle/10665/260291/978924 3512891-

spa.pdf; jsessionid=8202AA96D67C826359CDC64480EFB8B3 ?sequ ence $=1$

ONU, Organización de las Naciones Unidas. (1948). Declaración universal de los derechos humanos. Resolución de la asamblea general 217 A (iii) del 10 de diciembre de 1948. Recuperado de http://www.ordenjuridico.gob.mx/TratInt/Derechos\%20Humanos/ INST\%2000.pdf

ONU, Organización de las Naciones Unidas. (2002). Observación general No. 15 (2002). El derecho al agua (artículos 11 y 12 del "Pacto Internacional de Derechos Económicos, Sociales y Culturales"). Recuperado de http://www.acnur.org/t3/fileadmin/Documentos/BDL/2012/8789.p df?view $=1$ 
Tecnología y

Ciencias $₫$ Agua
2020, Instituto Mexicano de Tecnología del Agua

Open Access bajo la licencia CC BY-NC-SA 4.0

(https://creativecommons.org/licenses/by-nc-sa/4.0/)

ONU, Organización de las Naciones Unidas. (2010). El derecho humano al agua y al saneamiento (notas para los medios). Recuperado de http://www.un.org/spanish/waterforlifedecade/pdf/human_right_t o_water_and_sanitation_media_brief_spa.pdf

ONU, Organización de las Naciones Unidas. (2013). Objetivos de Desarrollo del Milenio (Informe de 2013. Podemos erradicar la pobreza). New York, EUA: Naciones Unidas. Recuperado de http://www.un.org/es/millenniumgoals/pdf/mdg-report-2013spanish.pdf

ONU \& OMS, Organización de las Naciones Unidas, Organización Mundial de la Salud. (2011). El derecho al agua. (Folleto informativo No. 35). Ginebra, Suiza: Naciones Unidas y Organización Mundial de la Salud. Recuperado de https://www.ohchr.org/Documents/Publications/FactSheet35sp.pd $f$

ONU \& CEPAL, Organización de las Naciones Unidas, Comisión Económica para América Latina y el Caribe. (2016). Agenda 2030 y los objetivos de desarrollo sostenible. Una oportunidad para América Latina y el Caribe. Santiago, Chile: Naciones Unidas y Comisión Económica para América Latina y el Caribe. Recuperado de http://www.sela.org/media/2262361/agenda-2030-y-losobjetivos-de-desarrollo-sostenible.pdf

Pérez, L. R. (2015). La nueva cultura del agua, el camino hacia una gestión sostenible. Causas e impactos de la crisis global del agua. Cuadernos de trabajo/Lan-koadernoak, Hegoa, (68), 53. Recuperado de 
Tecnología y

Ciencias $\mathrm{\approx}$ Agua
2020, Instituto Mexicano de Tecnología del Agua

Open Access bajo la licencia CC BY-NC-SA 4.0

(https://creativecommons.org/licenses/by-nc-sa/4.0/)

http://www.ehu.eus/ojs/index.php/hegoa/article/view/15672/135 86

Planque, B. (2002). Reflections on innovation networks: Contractual vs. "conventional" networks, 42nd Congress of the European Regional Science Association: "From Industry to Advanced Services Perspectives of European Metropolitan Regions", August 27th 31st, 2002, Dortmund, Germany, European Regional Science Association (ERSA), Louvain-la-Neuve.

PNUD, Programa de las Naciones Unidas para el Desarrollo. (2016). Captación y aprovechamiento de agua de lluvia en América Latina. Experiencias y conclusiones de un debate. Santiago, Chile: Programa de las Naciones Unidas para el Desarrollo.

Pol, E., \& Ville, S. (2009). Social innovation: Buzz word or enduring term? The Journal of Socio-Economics, (38), 878-885. DOI: 10.1016/j.socec.2009.02.011

Ribeiro, do N. G. A. (2018). El derecho al agua y su protección en el contexto de la Corte Interamericana de Derechos Humanos. Estudios Constitucionales, 16(1), 245-280. Recuperado de https://scielo.conicyt.cl/pdf/estconst/v16n1/0718-5200-estconst16-01-00245.pdf

Sagarpa, Secretaría de Agricultura, Ganadería, Desarrollo Rural, Pesca y Alimentación. (2013). Evaluación de Proyecto Estratégico de Seguridad Alimentaria (PESA) 2013. Informe final. México, DF, México: Secretaría de Agricultura, Ganadería, Desarrollo Rural, Pesca y Alimentación. 
Tecnología y

Ciencias $₫$ Agua
2020, Instituto Mexicano de Tecnología del Agua

Open Access bajo la licencia CC BY-NC-SA 4.0

(https://creativecommons.org/licenses/by-nc-sa/4.0/)

Salmón, G. E. (2012). El derecho humano al agua y los aportes del sistema interamericano de derechos humanos. Universitas. Revista de Filosofía, Derecho y Política, (16), 245-268. Recuperado de http://universitas.idhbc.es/n16/16-11.pdf

Salmón, E. (2013). Los (tímidos) aportes del derecho internacional a la construcción del derecho humano al agua. En: Hoogesteger, J. y Urteaga, P. (eds.). Agua e Inequidad. Discursos, políticas y medios de vida en la región Andina. Lima: IEP/Justicia Hídrica, 67-86. Recuperado de http://justiciahidrica.org/wpcontent/bibtex/pdf/05_HoogestegerUrteaga_Cap5.pdf

Secretaría de Gobernación. (2014). Constitución Política de los Estados Unidos Mexicanos, vigésima primera edición. México, DF, México: Secretaría de Gobernación. Recuperado de http://www.dof.gob.mx/constitucion/marzo_2014_constitucion.pdf

Semarnat, Secretaría de Medio Ambiente y Recursos Naturales. (2016). Atlas del agua en México 2016. Ciudad de México, México: Secretaría de Medio Ambiente y Recursos Naturales. Recuperado de http://201.116.60.25/publicaciones/AAM_2016.pdf

Semarnat \& Conagua, Secretaría de Medio Ambiente y Recursos Naturales, Comisión Nacional del Agua. (2017). Estadísticas del agua en México. Edición 2017. México, DF, México: Secretaría de Medio Ambiente y Recursos Naturales y Comisión Nacional del Agua. Recuperado de http://sina.conagua.gob.mx/publicaciones/EAM_2017.pdf 
Tecnología y

Ciencias $₫$ Agua
2020, Instituto Mexicano de Tecnología del Agua

Open Access bajo la licencia CC BY-NC-SA 4.0

(https://creativecommons.org/licenses/by-nc-sa/4.0/)

Smith, A. (2017). Innovación social, democracia y makerspaces. Revista Española del Tercer Sector, (36), 49-74. Recuperado de https://grassrootsinnovations. files.wordpress.com/2017/06/smith2017-revista_rets_n36.pdf

Van der Have, R. P., \& Rubalcaba, L. (2016). Social innovation research: An emerging area of innovation studies? Journals Research Policy, 45(9), 1923-1935. DOI: 10.1016/j.respol.2016.06.010

WHO, World Health Organization. (2003). The right to water. Recuperado de http://www2.ohchr.org/english/issues/water/docs/Right_to_Water .pdf

Windrum, P., Schartinger, D., Rubalcaba, L., Gallouj, F., \& Toivonen, M. (2016). The co-creation of multi-agent social innovations: A bridge between service and social innovation research. European Journal of Innovation Management, 19(2), 150-166. Recuperado de https://doi.org/10.1108/EJIM-052015-0033

Zwarteveen, M., \& Boelens, R. (2011a). La investigación interdisciplinaria referente a la temática de "justicia hídrica": unas aproximaciones conceptuales. En: Boelens, R., Cremers, L., \& Zwarteveen, M. (eds.). Justicia hídrica. Acumulación, conflicto y acción social (pp. 29-58). Lima, Perú: Instituto de Estudios Peruanos, Justicia Hídrica y Fondo Editorial Pontificia Universidad Católica del Perú. 
Tecnología y

Ciencias $₫$ Agua
2020, Instituto Mexicano de Tecnología del Agua

Open Access bajo la licencia CC BY-NC-SA 4.0

(https://creativecommons.org/licenses/by-nc-sa/4.0/)

Zwarteveen, M., \& Boelens, R. (2011b). Justicia hídrica: algunas reflexiones. En: Boelens, R., Cremers, L., \& Zwarteveen, M. (eds.). Justicia hídrica. Acumulación, conflicto y acción social (pp. 455-467). Lima, Perú: Instituto de Estudios Peruanos, Justicia Hídrica y Fondo Editorial Pontificia Universidad Católica del Perú. 